\title{
Slurry Water Regeneration after Hydraulic Mining
}

\author{
Galina Evmenova ${ }^{1, *}$, and Sergey Evmenov ${ }^{2}$ \\ ${ }^{1}$ T.F. Gorbachev Kuzbass State Technical University, Department of Mineral Processing, 650000 \\ Kemerovo, 28 Vesennya st., Russian Federation \\ ${ }^{2}$ T.F. Gorbachev Kuzbass State Technical University, Department of Coal Chemistry, Plastics and \\ Environment Protection Engineering, 650000 Kemerovo, 28 Vesennya st., Russian Federation
}

\begin{abstract}
Treatment and clarification of coal-day suspensions involve of whole range of technological processes, the efficiency of which depends significantly on the concentration of finely dispersed coal in the water-coal suspension. The behavior of flocculation of coal and clay suspensions with high molecular weight substances making possible to forecast the efficiency of polymer action while controlling the electrokinetic properties and aggregate stability of disperse systems has been studied. Aggregation of fine dispersal particles leads to the acceleration of their sedimentation and intensifies technological processes. The flocculant's efficiency depends on the molecular weight of a polymer and its structure, the charge value of its functional groups, and also the properties of solid particles' surfaces, methods of solution preparations etc. These factors must provide strong adsorption during the creation of aggregates and provide a significant influence on the flocculant consumption
\end{abstract}

\section{Introduction}

A distinct feature of a technological complex «hydraulic mine - processing plant» is an excessive amount of water arriving with raw coal to a plant (approximately three times more than it is necessary for the wet preparation). After separation of coal the water is recycled to a mine, i.e. a rigid link «hydraulic mine - plant» takes place.

In the present work a method of the slurry waters regeneration for the second usage at a hydraulic mine is specified (fig. 1). The reception of coal slurry is carried out as per the grades to the tanks of the hydraulic mining after preliminary deslurring on OSO comical screens. The product of 100-3 mm size is directed to a cycle of dressing on fine coal jigs. The slurry with particles of $3 \mathrm{~mm}$ size and less is headed to pyramid-shaped settling tank from which the condensed product $(3-0.5 \mathrm{~mm})$ is transferred to dressing, and the draining is thickened in radial thickeners. The condensed product is enriched by the flotation method, the draining is recycled as re-circulated water to the hydraulic mine. The content of the thin-dispersed particles in clarified water should not exceed 1 gram per 1 liter but in practice this value actually reaches $15 \mathrm{gr} / 1$, and consequently it is necessary to intensify the sedimentation process of the given dispersion.

\footnotetext{
*Corresponding author: galina-evmenova@yandex.ru
} 
As a matter of fact, the fine coal particles acquire similar negative charge in water environment what prevents them from convergence and aggregates formation. The surface forces affecting the fines of 50 micrometer and less in liquid phase are 100-1000 times greater the gravitation forces, therefore it is necessary to apply efficient methods of impact on the coal disperse system in order of its destabilizing [1-3].

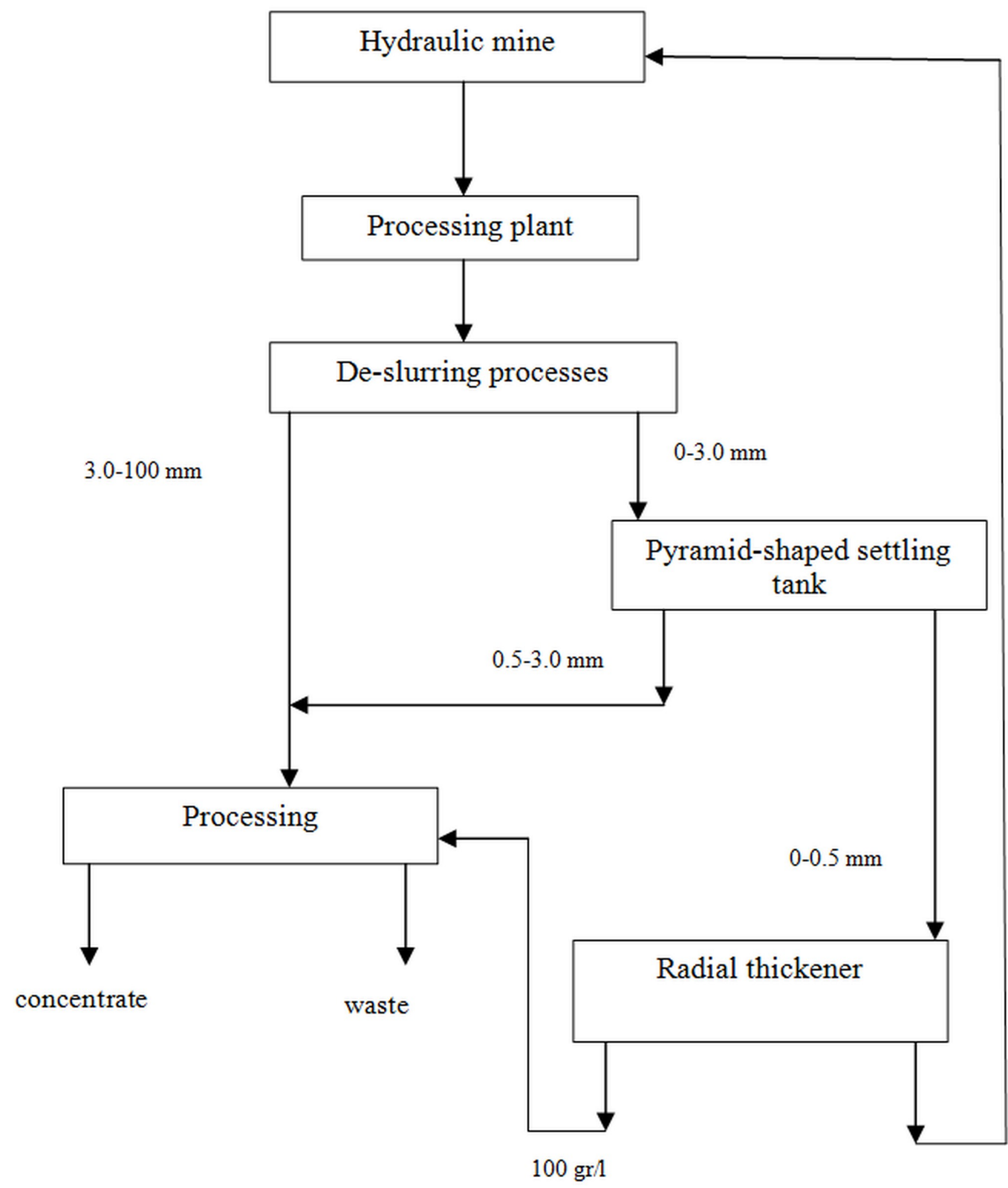

Fig. 1. Technological complex «hydraulic mine - processing plant».

\section{Materials and Methods}

One of the perspective ways to increase the efficiency of sedimentation of the thindispersed systems is an application of polymer flocculants. As the objects of study we utilized slurry water with the solid content of $15 \mathrm{gr} / 1$ and size of the fines of 45 micrometers and less, and industrial samples of anionic and cationic flocculants of Magnaflock type $(365,525,1440)$, having different molecular weight and ionic strength. 
The efficiency of the sedimentation process of coal slurry was evaluated by speed movement of the interface between «the clarified layer - the residue» in 1 liter glass barrels.

The results of the studies are given in fig. 2. It is evident that the rate of sedimentation at flocculants adding has been increased sharply, and the form of the curves for each polymer was different. Under the influence of M525 the rate of the sedimentation of the particles (curve 1) increased with the rising of the flocculant consumption in the solution and reached its maximum rate of $0.41 \mathrm{~cm} / \mathrm{s}$ at concentration of $4 \mathrm{mg} / \mathrm{l}$, the further increase of the flocculant concentration did not change the rate. At the same time at adding of the insignificant amount of M365 (1 mg/l) into initial slurry the sedimentation rate increased

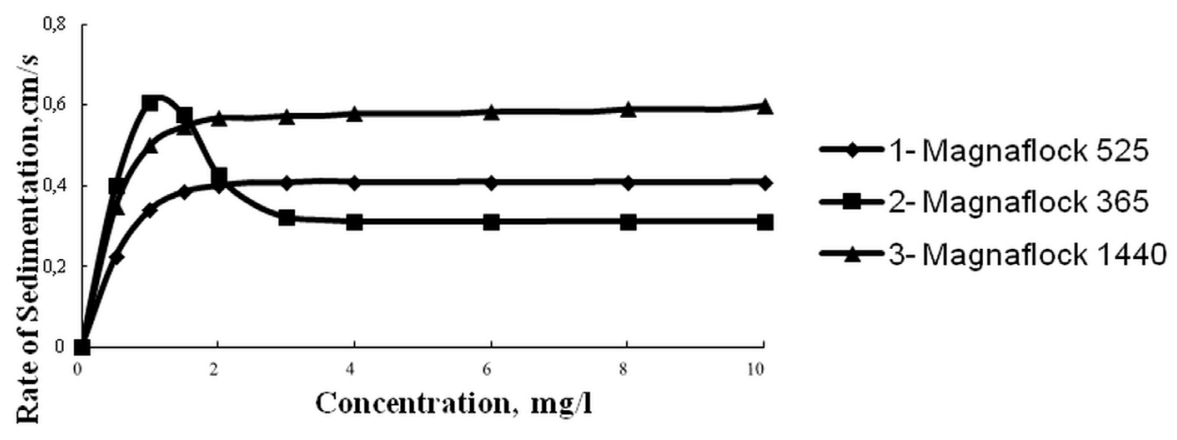

Fig. 2. Ratio of Coal Particles Sedimentation Rate to Magnaflock Concentration.

sharply and reached its maximum of $0.61 \mathrm{~cm} / \mathrm{s}$ (curve 2). It could be explained by the fact that the applying flocculant (M365) has high molecular weight and greater size of macromolecules that is very important for the bridge type of flocculation since a larger macromolecule can link the greater number of solid particles into an aggregate. With the increase of the flocculant concentration with the greater molecular weight (M365) the steric factor also increased and rate of sedimentation is sharply reduced. It can be seen on fig. 2, curve 2. At the concentration of $2 \mathrm{mg} / \mathrm{l}$ the sedimentation rate dropped down up to 0.42 $\mathrm{cm} / \mathrm{s}$, and at $6 \mathrm{mg} / 1$ decreased to the constant value of $0.31 \mathrm{~cm} / \mathrm{s}$. In all experiments with the usage of anionic flocculants the draining remained turbid.

Influencing on slurry of the cationic M1440 the rate of the sedimentation of the particles was rather high, about $0.5 \mathrm{~cm} / \mathrm{s}$ at flocculant concentration in solution equal to $1 \mathrm{mg} / \mathrm{l}$ (fig. 2 , curve 3 ). With growth of the flocculant consumption the sedimentation rate increased and the draining remained transparent. According to existing data [4-10], the flocculation of the thin particles occurs due to the neutralization of the surface charge at adsorption of the oppositely charged links on the solid particles surface. Thus, it is supposed that flocculant's macromolecules bind to the surface by the large number of the contracts, «turning» and forming a «mosaic» pattern from approximately equal number of charges of different sign. Besides in the works [11-12] it was illustrated that the flocculation of dispersions by the cationic flocculant flows in different ways: due to the decrease of the charge and potential of the particles, and due to the formation of the «bridge» links between particles throughout adsorbed macromolecules. As a result of it there is an aggregation of thin slurry to the larger flocks.

Thereby, the cationic polymeric flocculants that have high molecular weight can combine those two mechanisms and provide not only a sedimentation rate increase, but also a significant reduction of the fine particles concentration in the clarified water. 
Besides, the additional study of clay particles in flotation waste was held under similar conditions. The experimental curves are given in fig. 3. Comparing the both curves (fig. 2 and fig. 3) it is evident that the behavior of curves is practically identical. It proves that it is not casual results but regularity which don't depend upon the type of the flocculant and hydration of the surface of the mineral dispersions.

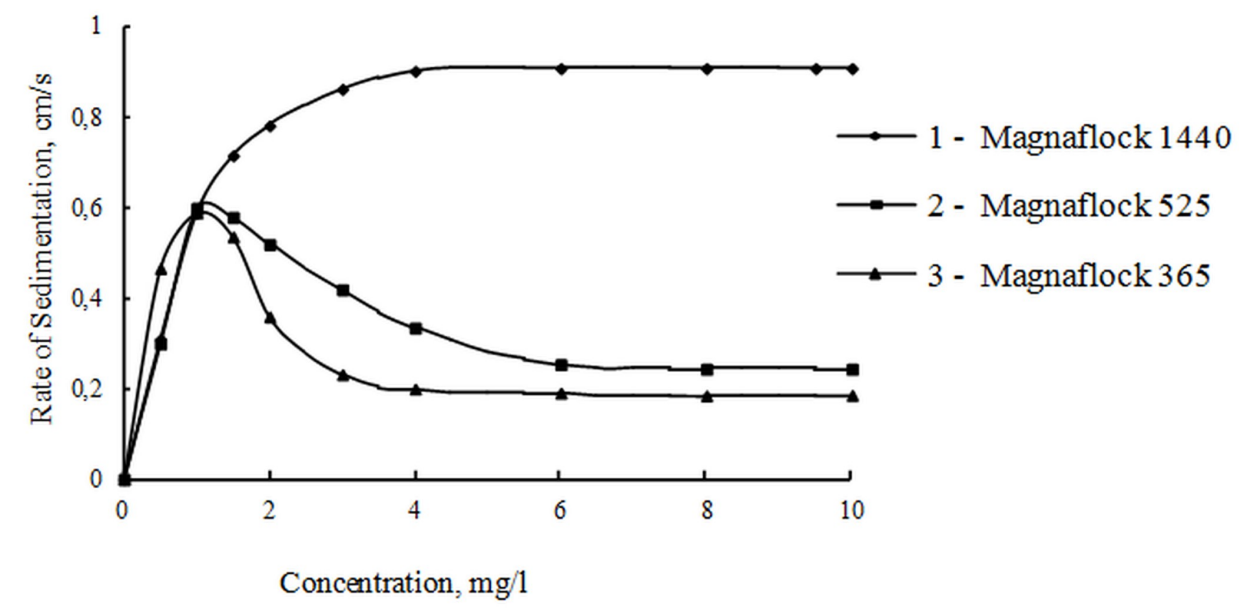

Fig. 3. Flotation Waste Particles Sedimentation Rate to Magnaflock Concentration Ratio.

It must be noted that the flocculation process must be conducted under the minimal shearing strain to exclude the destruction of aggregates when moved and ensure an effective purification of slurred water [13].

Special attention must be given to the preparation of the flocculant solutions. [14]. When under industrial conditions, the existing methods of flocculant solutions preparations cannot always ensure homogeneity of the solution. It leads to significant differences in the properties of those solutions and, in that case, flocculants will be present in the pulp in a form of a gel or associates. Also, the mechanical and chemical influence on the macromolecules is not always completely eliminated, and it leads to their destruction [15]. In the end, it lowers the flocculation efficiency and increases the expenses on high-priced polymers

\section{Conclusions}

The research of the anionic and cationic flocculants usage in purification of the coal and clay suspensions was conducted.

It has been established that the usage of cationic flocculant Magnaflock 1440, as opposed to the usage of anionic flocculants, allows to not only enhance the particles sedimentation rate, but also obtain a clean draining from the radial thickener and to provide the supply of the regenerated water to the hydraulic mine.

The studies prove that there is no need in covering of the entire mineral surface by the layer of macromolecules, but it's quite enough of the «mosaic» pattern bind by the flocculant, what allows to aggregate of the thin disperse particles and intensify their sedimentation at the small consumption.

\section{References}


1. T. W. Healy, V.K. La Mer, J. Colloid Interface Sci. 19, 323 (1964)

2. W. E. Walles J. Colloid Interface Sci. 27, 797 (1968)

3. B. Vincent, Adv. Colloid Interface Sci. 4, 196 (1974)

4. J. Gregory, Solid/Liquid Dispersions. (London, Academic Press Inc., 1987)

5. D. N. Thomas, S.J. Judd, N. Fawcett, Water Res. 33, 1579 (1998)

6. V. K. La Mer, Disc. Faraday Soc. 42, 248 (1966)

7. P. R. Sperry, J. Colloid Interface Sci. 87, 375 (1982)

8. P. R. Sperry, J. Colloid Interface Sci. 99, 97 (1984)

9. W. E. Walles, J. Colloid Interface Sci. 27, 797 (1968)

10. J. Gregory, Traus. Farasay Soc. 65, 2260 (1969)

11. J. Gregory, J. Colloid Interface Sci. 42, 448 (1973)

12. G. L. Evmenova, J. Min. Sci. 44, 298 (2008)

13. G. L. Evmenova, A. A. Baichenko, J. Min. Sci, 36, 518 (2000)

14. M. H Al-Rashed, M. Lemanowicz, A. T. Gierczycki, Int. J. Miner. Process. 104:105, 1 (2012)

15. S. D. Evmenov, G. L. Evmenova, Chinese Coal in the XXI Century, Mining, Green and Safety Taishan Academic Forum - Project on Mine Disaster Prevention and Control, 424 (2014) 